\title{
Echocardiographic predictors of intraoperative right ventricular dysfunction: a 2D and speckle tracking echocardiography study
}

Lisa Q. Rong ${ }^{1}$, Brian Yum², Christiane Abouzeid ${ }^{2}$, Maria Chiara Palumbo², Lillian R. Brouwer ${ }^{2}$, Richard B. Devereux², Leonard N. Girardi ${ }^{3}$, Jonathan W. Weinsaft ${ }^{2}$, Mario Gaudino ${ }^{3}$ and Jiwon Kim² ${ }^{2 *}$

\begin{abstract}
Background: Intraoperative or post procedure right ventricular (RV) dysfunction confers a poor prognosis in the post-operative period. Conventional predictors for RV function are limited due the effect of cardiac surgery on traditional RV indices; novel echocardiographic techniques hold the promise to improve RV functional stratification.

Methods: Comprehensive echocardiographic data were collected prospectively during elective cardiac surgery. Tricuspid annular plane systolic excursion (TAPSE), peak RV systolic velocity ( ${ }^{\prime}$ ), and RV fractional area change (FAC) were quantified on transesophageal echo (TEE). RV global and regional (septal and free wall) longitudinal strain was quantified using speckle-tracking echo in RV-focused views. Two intraoperative time points were used for comparison: pre-sternotomy (baseline) and after chest closure.

Results: The population was comprised of 53 patients undergoing cardiac surgery [15.1\% coronary artery bypass graft (CABG) only, 28.3\% valve only, 50.9\% combination (e.g. valve/CABG, valve/aortic graft) surgeries], among whom 38\% had impaired RV function at baseline defined as RV FAC $<35 \%$. All conventional RV functional indices including TAPSE, $S^{\prime}$ and FAC declined immediately following CPB $(1.5 \pm 0.3 \mathrm{vs} .1 .1 \pm 0.3 \mathrm{~cm}, 8.0 \pm 2.1 \mathrm{vs} .6 .2 \pm 2.5 \mathrm{~cm} / \mathrm{s}, 36.8 \pm 9.3 \mathrm{vs} .29 .3 \pm$ $10.6 \% ; p<0.001$ for all). However, left ventricular (LV) and RV hemodynamic parameters remained unchanged (LV ejection fraction (EF): $56.8 \pm 13.0$ vs. $55.8 \pm 12.9 \% ; p=0.40$, pulmonary artery systolic pressure (PASP): $26.5 \pm 7.4$ vs $27.3 \pm 6.7 \mathrm{mmHg} ; p=0.13$ ). Speckle tracking echocardiographic data demonstrated a significant decline in RV global longitudinal strain (GLS) [19.0 \pm 6.5 vs. $13.5 \pm 6.9 \%, p<0.001]$. Pre-procedure FAC, GLS and free wall strain predicted RV dysfunction at chest closure (34.7 \pm 9.1 vs. $41.6 \pm 8.1 \%, p=0.01,17.7 \pm 6.5$ vs. $21.8 \pm 5.4 \% ; p=0.03,20.3 \pm 6.4$ vs. $24.2 \pm$ 5.8\%; $p=0.04$ ), whereas traditional linear RV indices such as TAPSE and RV $S^{\prime}$ at baseline had no impact on intraoperative RV dysfunction ( $p=$ NS for both).
\end{abstract}

Conclusions: Global and regional RV function, as measured by 2D indices and strain, acutely decline intraoperatively. Impaired RV strain is associated with intraoperative RV functional decline and provides incremental value to traditional RV indices in predicting those who will develop RV dysfunction.

Keywords: Right ventricular function, Cardiac surgery, 2D speckle tracking, Intraoperative transesophageal echocardiography

\footnotetext{
* Correspondence: jik9027@med.cornell.edu

2Department of Medicine/Cardiology Division, Weill Cornell Medical College,

525 East 68th Street, New York, NY 10021, USA

Full list of author information is available at the end of the article
}

(c) The Author(s). 2019 Open Access This article is distributed under the terms of the Creative Commons Attribution 4.0 International License (http://creativecommons.org/licenses/by/4.0/), which permits unrestricted use, distribution, and reproduction in any medium, provided you give appropriate credit to the original author(s) and the source, provide a link to the Creative Commons license, and indicate if changes were made. The Creative Commons Public Domain Dedication waiver (http://creativecommons.org/publicdomain/zero/1.0/) applies to the data made available in this article, unless otherwise stated. 


\section{Background}

RV dysfunction is common; it occurs in nearly one fourth of patients who undergo cardiac surgery. Intraoperative or post procedure RV dysfunction is linked to high postoperative mortality $[1,2]$. However, RV assessment can be challenging due to its anterior location and complex crescent-shaped geometry, which pose particular imaging difficulties in the intraoperative setting. Prior studies have shown that commonly used indices of RV function such as tricuspid annular plane systolic excursion (TAPSE) can be altered by pericardiotomy itself $[3,4]$. For example, decrements in longitudinal shortening have been shown to result in gains in transverse shortening [5] thereby further limiting traditionally used longitudinal measures of RV performance, TAPSE and RV S'. In addition to these limitations, longitudinal RV contraction in the intraoperative setting has been shown to reflect geometric changes related to cardiac surgery itself, rather than due to true functional decline [6].

Myocardial deformation via two-dimensional speckle tracking echocardiography (2D STE) provides incremental value in prognostic stratification as compared to traditional indices in a wide range of cardiac conditions including heart failure, coronary artery disease and pulmonary hypertension [7-9]. However, its role in the intraoperative setting has yet to be established. In particular, the angleindependent nature of speckle tracking has the potential to overcome limitations of 2D linear indices of TAPSE and S' and is thereby uniquely suited for RV assessment in this setting. In addition, RV deformation has been shown to detect subclinical RV dysfunction and therefore may be of utility in predicting post-operative outcomes $[10,11]$. The goals of this study were: 1 . to address the acute intraoperative impact on RV function by using both standard 2D and deformation echo indices; and 2. to test the performance of conventional and deformation indices to predict intraoperative RV dysfunction.

\section{Methods}

\section{Study population}

Patients were enrolled prospectively from 11/2017 to the present as part of an established protocol (PALACS Trial) at Weill Cornell Medical College [12].

\section{Imaging protocol \\ Echocardiography}

Comprehensive TEEs were performed prior to sternotomy (baseline) and after chest closure (post procedure) using commercial equipment (GE Vivid 7 [GE Healthcare, Madison, WI]) and Phillips iE33 [Phillips Medical Systems, Andover, MA] echo systems). TEEs were interpreted by experienced investigators within a high-volume laboratory, for which expertise and reproducibility for quantitative RV indices have been validated $[13,14]$.

\section{D TEE}

RV systolic function was quantified using tricuspid annular plane systolic excursion (TAPSE), right ventricular systolic myocardial velocity (RV-S') and fractional area of change (FAC), which were acquired in accordance with consensus guidelines [15]. TAPSE was measured on M-mode as the systolic excursion of the lateral tricuspid annulus along its longitudinal plane and RV-S' on tissue Doppler as the peak tricuspid annular velocity of excursion. FAC was measured via planimetry of end-diastolic and end-systolic contours in mid-esophageal 4-chamber orientation. The established FAC cut off $(<35 \%)$ was used to identify post procedure (intraoperative) RV dysfunction [16]. Right atrial area was calculated by planimetry in end systole in mid-esophageal 4-chamber view and volume was quantified by area-length method.

\section{Speckle-tracking strain analysis}

2D echocardiographic images were analyzed offline for deformation analysis (2D CPA; TomTec Imaging Systems). Strain measurements were performed by an investigator experienced in the interpretation of echocardiographic images, blinded to the results of the 2D measurements. Each image was acquired in the mid-esophageal four-

Table 1 Clinical Characteristics

\begin{tabular}{|c|c|c|c|c|}
\hline & $\begin{array}{l}\text { Overall } \\
(n=53)\end{array}$ & $\begin{array}{l}\text { RV Dysfunction }+^{a} \\
(n=37)\end{array}$ & $\begin{array}{l}\text { RV Dysfunction - } \\
(n=16)\end{array}$ & $p$ \\
\hline Age (years) & $63 \pm 11$ & $61 \pm 11$ & $67 \pm 10$ & 0.09 \\
\hline Male gender & $69.8 \%(37)$ & $75.7 \%(28)$ & $54.3 \%(9)$ & 0.20 \\
\hline BMI & $27.8 \pm 4.6$ & $28.2 \pm 4.7$ & $27.2 \pm 4.3$ & 0.60 \\
\hline \multicolumn{5}{|l|}{ CV Risk Factors } \\
\hline Hypertension & $78.8 \%(41)$ & $73.0 \%(27)$ & $87.5 \%(14)$ & 0.47 \\
\hline Diabetes & $11.3 \%(6)$ & $13.5 \%(5)$ & $6.3 \%(1)$ & 0.66 \\
\hline $\begin{array}{l}\text { Prior } \\
\text { Myocardial } \\
\text { Infarction }\end{array}$ & $9.4 \%(5)$ & $13.5 \%(5)$ & $0.0 \%(0)$ & 0.31 \\
\hline \multicolumn{5}{|l|}{ Operation } \\
\hline CABG Only & $15.1 \%(8)$ & $18.9 \%(7)$ & $6.3 \%(1)$ & 0.41 \\
\hline $\begin{array}{l}\text { Valve } \\
\text { Surgery Only }\end{array}$ & $28.3 \%(15)$ & $29.7 \%(11)$ & $25.0 \%(4)$ & 1.00 \\
\hline $\begin{array}{l}\text { Concurrent } \\
\text { Aortic } \\
\text { Surgery }\end{array}$ & $39.6 \%(21)$ & $37.8 \%(14)$ & $43.8 \%(7)$ & 0.69 \\
\hline $\begin{array}{l}\text { Aortic } \\
\text { Surgery Only }\end{array}$ & $3.8 \%(2)$ & $5.4 \%(2)$ & 0\% (0) & 1.00 \\
\hline Combination & $50.9 \%(27)$ & $45.9 \%(17)$ & $62.5 \%(10)$ & 0.27 \\
\hline Other & $1.9 \%(1)$ & $0 \%(0)$ & $6.3 \%(1)$ & 0.30 \\
\hline $\begin{array}{l}\text { NYHA Class } \\
(\mathrm{I} / \mathrm{II} / \mathrm{II} / \mathrm{IV})\end{array}$ & $\begin{array}{l}72 \%(36) / 18 \% \\
(9) / 10 \%(5) / \\
0 \%(0)\end{array}$ & $\begin{array}{l}66 \%(23) / 23 \% \\
(8) / 11 \%(4) / \\
0 \%(0)\end{array}$ & $\begin{array}{l}86 \%(13) / 7 \% \\
(1) / 7 \%(1) / \\
0 \%(0)\end{array}$ & 0.15 \\
\hline
\end{tabular}

$B M I$ body mass index, $C V$ cardiovascular, CABG coronary artery bypass graft, NYHA New York Heart Association

${ }^{\mathrm{a}}$ Categorized based on established echo cut off FAC $<35 \%$ (post chest closure) 
Table 2 Echocardiographic and Hemodynamic Parameters

\begin{tabular}{|c|c|c|c|c|}
\hline & $\begin{array}{l}\text { Overall } \\
(n=53)\end{array}$ & $\begin{array}{l}\text { RV Dysfunction }+^{a} \\
(n=37)\end{array}$ & $\begin{array}{l}\text { RV Dysfunction - } \\
(n=16)\end{array}$ & $p$ \\
\hline \multicolumn{5}{|l|}{ Baseline } \\
\hline \multicolumn{5}{|l|}{ LV } \\
\hline $\operatorname{EDV}\left(\mathrm{mL} / \mathrm{m}^{2}\right)$ & $104.1 \pm 45.5$ & $108.4 \pm 39.6$ & $93.1 \pm 58.3$ & 0.31 \\
\hline $\operatorname{ESV}\left(\mathrm{mL} / \mathrm{m}^{2}\right)$ & $48.0 \pm 31.3$ & $51.6 \pm 30.9$ & $39.0 \pm 31.7$ & 0.22 \\
\hline EF (\%) & $56.8 \pm 13.0$ & $55.9 \pm 14.0$ & $59.2 \pm 10.0$ & 0.45 \\
\hline \multicolumn{5}{|l|}{ RV } \\
\hline $\mathrm{EDA}\left(\mathrm{cm}^{2}\right)$ & $19.3 \pm 6.9$ & $19.4 \pm 6.7$ & $19 \pm 7.5$ & 0.85 \\
\hline ESA $\left(\mathrm{cm}^{2}\right)$ & $12.2 \pm 4.9$ & $12.6 \pm 4.6$ & $11.2 \pm 5.4$ & 0.34 \\
\hline TAPSE (cm) & $1.5 \pm 0.4$ & $1.4 \pm 0.3$ & $1.6 \pm 0.4$ & 0.14 \\
\hline $\mathrm{S}^{\prime}(\mathrm{cm} / \mathrm{s})$ & $8.0 \pm 2.1$ & $7.9 \pm 2.4$ & $8.5 \pm 2.4$ & 0.48 \\
\hline GLS (\%) & $-19.0 \pm 6.5$ & $-17.7 \pm 6.5$ & $-21.8 \pm 5.4$ & 0.03 \\
\hline Septal Strain (\%) & $-17.9 \pm 5.9$ & $-16.9 \pm 5.5$ & $-20.0 \pm 6.4$ & 0.08 \\
\hline Free Wall Strain (\%) & $-21.5 \pm 6.4$ & $-20.3 \pm 6.4$ & $-24.2 \pm 5.8$ & 0.04 \\
\hline FAC (\%) & $36.8 \pm 9.3$ & $34.7 \pm 9.1$ & $41.6 \pm 8.1$ & 0.01 \\
\hline \multicolumn{5}{|l|}{ RA } \\
\hline Area $\left(\mathrm{cm}^{2}\right)$ & $14.9 \pm 4.9$ & $14.4 \pm 4.8$ & $16 \pm 5.3$ & 0.35 \\
\hline Length $(\mathrm{cm})$ & $3.9 \pm 0.8$ & $3.8 \pm 0.7$ & $4.1 \pm 0.9$ & 0.33 \\
\hline Volume Index $\left(\mathrm{mL} / \mathrm{m}^{2}\right)$ & $30.3 \pm 13.9$ & $28.6 \pm 13.1$ & $34.4 \pm 15.5$ & 0.21 \\
\hline \multicolumn{5}{|l|}{ Hemodynamics } \\
\hline LV EDP (mmHg) & $13.8 \pm 4.6$ & $13.3 \pm 4.0$ & $15.3 \pm 5.9$ & 0.23 \\
\hline PASP $(\mathrm{mmHg})$ & $26.5 \pm 7.4$ & $27.0 \pm 7.3$ & $25.5 \pm 7.9$ & 0.50 \\
\hline PADP $(\mathrm{mmHg})$ & $10.5 \pm 4.0$ & $10.9 \pm 3.9$ & $9.8 \pm 4.1$ & 0.34 \\
\hline RAP $(\mathrm{mmHg})$ & $7.2 \pm 2.7$ & $7.6 \pm 2.8$ & $6.4 \pm 2.6$ & 0.13 \\
\hline RV CO (L) & $4.6 \pm 1.8$ & $4.5 \pm 1.9$ & $4.8 \pm 1.6$ & 0.67 \\
\hline \multicolumn{5}{|l|}{ Post procedure } \\
\hline \multicolumn{5}{|l|}{ LV } \\
\hline $\mathrm{EDV}\left(\mathrm{mL} / \mathrm{m}^{2}\right)$ & $79.7 \pm 30.3$ & $82.2 \pm 27.2$ & $73.1 \pm 37.5$ & 0.36 \\
\hline $\operatorname{ESV}\left(\mathrm{mL} / \mathrm{m}^{2}\right)$ & $37.0 \pm 20.5$ & $38.7 \pm 19.2$ & $32.8 \pm 23.6$ & 0.39 \\
\hline EF (\%) & $55.8 \pm 12.9$ & $54.1 \pm 13.0$ & $60.0 \pm 12.2$ & 0.17 \\
\hline \multicolumn{5}{|l|}{ RV } \\
\hline TAPSE (cm) & $1.1 \pm 0.3$ & $1.1 \pm 0.3$ & $1.1 \pm 0.4$ & 0.94 \\
\hline $\mathrm{S}^{\prime}(\mathrm{cm} / \mathrm{s})$ & $6.2 \pm 2.5$ & $6.0 \pm 2.3$ & $6.7 \pm 2.9$ & 0.41 \\
\hline GLS (\%) & $-13.5 \pm 6.9$ & $-10.1 \pm 4.3$ & $-21.2 \pm 5.3$ & $<0.001$ \\
\hline Septal Strain (\%) & $-12.4 \pm 6.6$ & $-9.9 \pm 5.2$ & $-18.2 \pm 5.9$ & $<0.001$ \\
\hline Free Wall Strain (\%) & $-15.5 \pm 7.8$ & $-12.4 \pm 5.6$ & $-22.8 \pm 7.6$ & $<0.001$ \\
\hline FAC (\%) & $29.3 \pm 10.6$ & $24.0 \pm 6.9$ & $41.7 \pm 6.6$ & $<0.001$ \\
\hline \multicolumn{5}{|l|}{ Hemodynamics } \\
\hline PASP (mmHg) & $27.3 \pm 6.7$ & $27.8 \pm 6.6$ & $26.1 \pm 6.7$ & 0.39 \\
\hline PADP $(\mathrm{mmHg})$ & $11.2 \pm 4.3$ & $11.5 \pm 4.3$ & $10.6 \pm 4.3$ & 0.49 \\
\hline RAP (mmHg) & $8.5 \pm 3.0$ & $8.8 \pm 3.0$ & $7.9 \pm 3.1$ & 0.37 \\
\hline RV CO (L) & $5.5 \pm 1.3$ & $5.5 \pm 1.3$ & $5.5 \pm 1.3$ & 0.98 \\
\hline
\end{tabular}

$L V$ left ventricle, $R V$ right ventricle, $R A$ right atrium, $E D V$ end diastolic volume, $E D S$ end systolic volume, $E F$ ejection fraction, $E D A$ end diastolic area, $E S A$ end systolic area, TAPSE tricuspid annular plane systolic excursion, $S^{\prime}$ peak systolic velocity, GLS global longitudinal strain, FAC fractional area of change, EDP end diastolic pressure, $P A S P$ pulmonary artery systolic pressure, PADP pulmonary artery diastolic pressure, RAP right atrial pressure, $C O$ cardiac output. Bold values indicate $p<0.05$

${ }^{\text {a } C a t e g o r i z e d ~ b a s e d ~ o n ~ e s t a b l i s h e d ~ e c h o ~ c u t ~ o f f ~ F A C ~}<35 \%$ (post chest closure) 

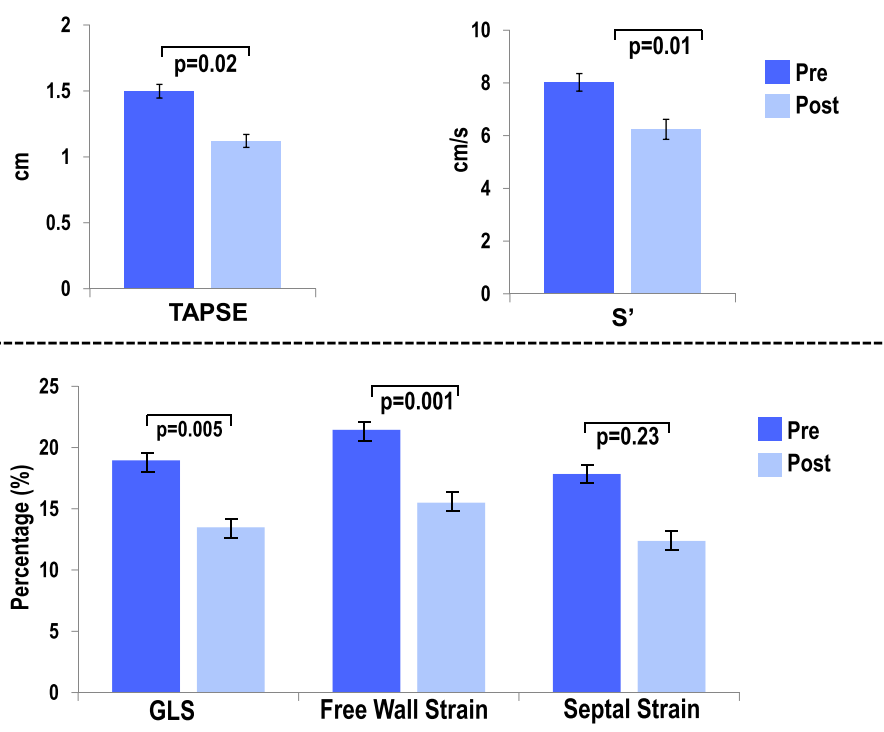

Fig. 1 RV parameters including linear and deformational indices decline intraoperatively. GLS decline is driven predominantly by impairments in free wall strain as there is no difference in interventricular septal deformation post procedure $(p=0.23)$

chamber view of the whole RV cavity and with a frame rate $>50 \mathrm{~Hz}$ for analysis of RV strain. The RV enddiastolic endocardial border was manually traced and tracked automatically frame-by-frame throughout the cardiac cycle. Endocardial contour was manually adjusted when necessary to optimize tracking.

\section{Statistical analysis}

Comparisons between groups were made using Student's t-test (expressed as mean \pm standard deviation) for continuous variables. Categorical variables were compared using Chi-square or, when fewer than 5 expected outcomes per cell, Fisher's exact test. Bivariate correlation coefficients, as well as regression analyses were used to evaluate univariable associations between continuous variables. Multivariate modeling was performed via logistic regression and echo indices were tested as continuous variables. Inter-rater and intra reliability was calculated using the intraclass-correlation coefficient. Statistical calculations were performed using SPSS 22.0 (SPSS Inc. [Chicago, IL]). Two-sided $p<0.05$ was considered indicative of statistical significance.

\section{Results}

The study population included 53 patients who underwent cardiac surgery with dedicated TEE for RV assessment at baseline and post procedure. Intraoperative RV dysfunction was defined as RV FAC $<35 \%$ post procedure. In this population, $38 \%$ had RV dysfunction at baseline and over two thirds (70\%) had some degree of RV dysfunction post procedure. Table 1 details clinical characteristics of the population, stratified by the presence or absence of TEE-verified intraoperative RV dysfunction.
As shown, $15.1 \%$ coronary artery bypass graft (CABG) only, $28.3 \%$ valve only, $50.9 \%$ combination (e.g. valve/ CABG, valve/aortic graft) surgeries; operation type had no impact on RV function. With respect to clinical characteristics, there were no differences between cardiovascular risk factors. Similarly, there were no differences in symptom status pre-operatively as characterized via New York Heart Association (NYHA) class $(p=0.15)$.

Table 2 demonstrates LV, RA, RV and hemodynamic indices at baseline and post procedure in relation to RV dysfunction. As shown, RV echocardiographic indices including conventional parameters and global longitudinal strain declined after chest closure ( $p<0.05$ for all). In support of the concept that RV functional decline is driven predominantly by effects on the RV free wall, there was no significant change in post procedure interventricular septal deformation ( $p=0.23$ ) (Fig. 1). When examining predictors for RV dysfunction post chest closure, baseline FAC, GLS and free wall strain were impaired in those patients with intraoperative RV dysfunction ( $34.7 \pm 9.1$ vs. $41.6 \pm 8.1 \%$; $p=$ $0.01,17.7 \pm 6.5$ vs. $21.8 \pm 5.4 \% p=0.03,20.3 \pm 6.4$ vs. $24.2 \pm$ $5.8 \% ; p=0.04$, respectively). On the other hand, traditional linear RV indices such as TAPSE and $\mathrm{S}^{\prime}$ had no impact on post chest closure RV dysfunction $(1.4 \pm 0.3$ vs. $1.6 \pm 0.4$ and $7.9 \pm 2.4$ vs. $8.5 \pm 2.4$; $p=\mathrm{NS}$ for both). Figure 2 represents a patient who developed intraoperative RV dysfunction with baseline impaired RV deformation and normal function as defined as FAC $>35 \%$.

Regarding LV parameters, there were no differences in baseline or post chest closure LV volumes and LV ejection fraction when stratified by intraoperative RV dysfunction. This finding adds to the concept that intraoperative RV dysfunction occurs independently of LV performance. 


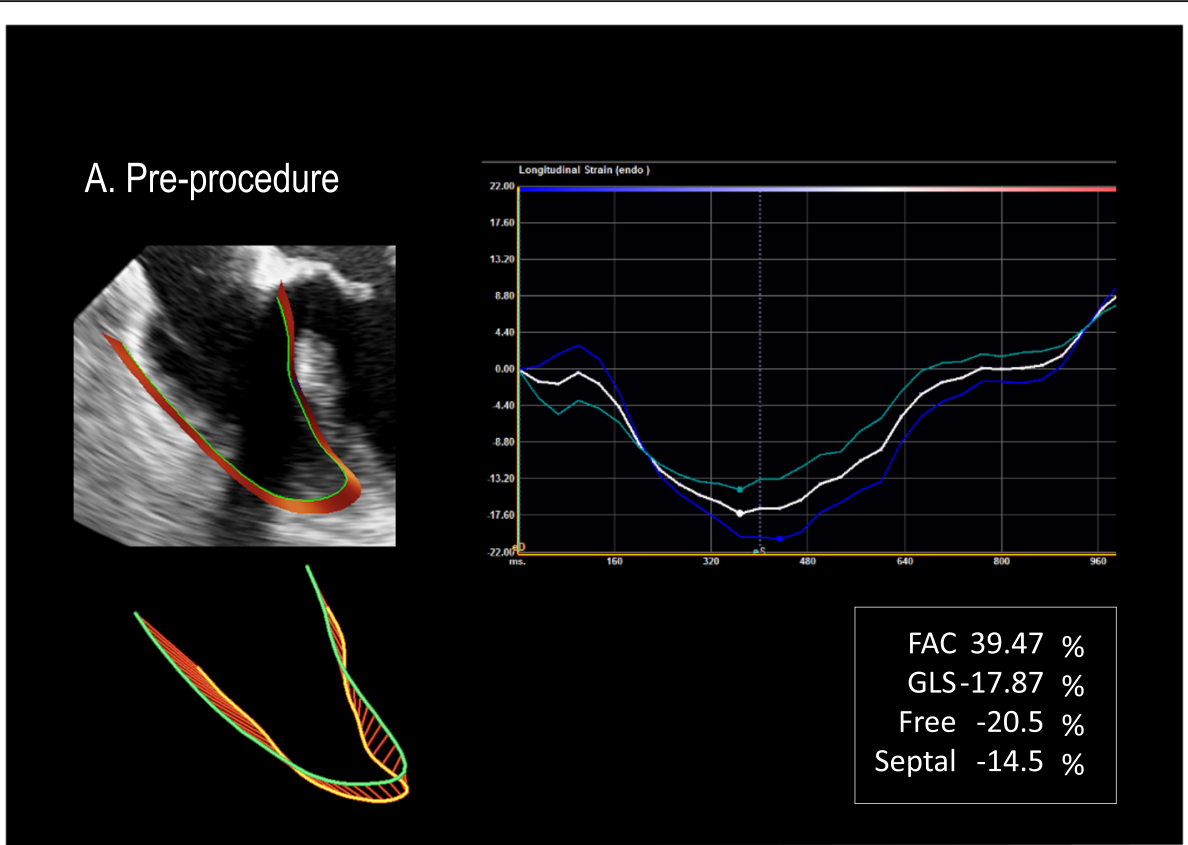

B. Post-procedure
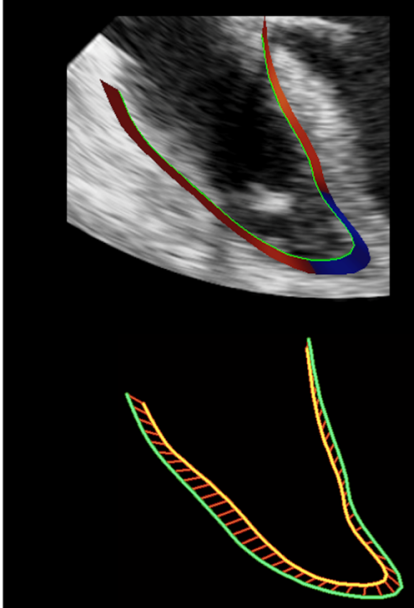

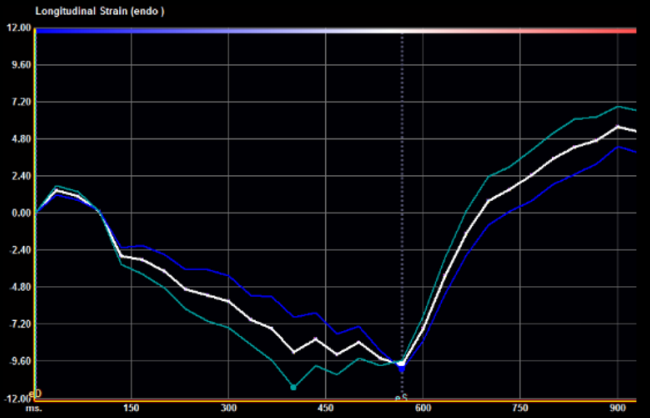

FAC $25.37 \%$

GLS - $10.43 \%$

Free $-10.1 \%$

Septal $-11.3 \%$

Fig. 2 a Representative example of pre-procedural TEE-derived RV strain analysis acquired in a patient undergoing cardiac surgery. b Postprocedural TEE analysis as acquired in the same patient: As shown, despite normal conventional index (FAC), this patient had impaired RV strain which is a risk factor for post procedure RV dysfunction

Table 3 Multivariate Regression for Post Procedure (Intraoperative) RV Dysfunction

\begin{tabular}{lccccc}
\hline Variable & Univariate Regression & & \multicolumn{2}{l}{$\begin{array}{l}\text { Multivariate Regression Chi } \\
\text { Square }=25.3, p<0.001\end{array}$} \\
\cline { 2 - 3 } & $\begin{array}{l}\text { Odds Ratio (95\% } \\
\text { Confidence Interval) }\end{array}$ & $p$ & \multicolumn{2}{l}{$\begin{array}{l}\text { Odds Ratio }(95 \% \\
\text { Confidence Interval) }\end{array}$} & $p$ \\
\hline $\begin{array}{l}\text { Free Wall } \\
\text { Strain }\end{array}$ & $1.33(1.13-1.56)$ & $<\mathbf{0 . 0 0 1}$ & $1.24(1.01-1.53)$ & $\mathbf{0 . 0 4}$ \\
$\begin{array}{l}\text { Septal } \\
\text { Strain }\end{array}$ & $1.29(1.12-1.49)$ & $<\mathbf{0 . 0 0 1}$ & $1.10(0.90-1.34)$ & 0.36 \\
\hline
\end{tabular}

Bold values indicate $p<0.05$
Hemodynamic indices, including pre and post pulmonary artery (PA) and right atrial (RA) pressures, also had no association with development of RV dysfunction after chest closure. Table 3 reports multivariate analysis concerning RV strain components for prediction of RV dysfunction. As shown, baseline free wall RV strain was independently associated with post-procedure RV dysfunction (OR 1.24 [CI 1.01 to 1.53$] p=0.04$ ) even after controlling for septal wall strain. These results indicate that post procedure RV dysfunction is closely linked to altered RV free wall contraction 
Table 4 Reproducibility

\begin{tabular}{cccccccc}
\hline & \multicolumn{2}{l}{ Inter-observer Reproducibility } & & \multicolumn{3}{l}{ Intra-observer Reproducibility } \\
\cline { 2 - 3 } & Mean \pm SD & Intraclass Correlation Coefficient & Limits of Agreement & & Mean \pm SD & Intraclass Correlation Coefficient & Limits of Agreement \\
\hline RV GLS & $-0.9 \pm 4.5$ & 0.85 & -9.6 to 7.9 & & $0.1 \pm 3.1$ & 0.92 & -6.0 to 6.3 \\
\hline
\end{tabular}

rather than interventricular septal function. Table 4 shows the intra-observer and interobserver measurements for 15 cases as well as the intraclass coefficient. As shown, the intraclass correlation coefficient ranged from 0.92 between measurements and 0.85 between observers.

\section{Discussion}

The primary aim of this study was to characterize and predict the acute intraoperative change in RV function using established deformational RV techniques. The findings of this study are as follows: 1 . RV dysfunction occurs in over two thirds of patients undergoing cardiac surgery and is associated with impaired RV global longitudinal strain but not conventional 2D RV parameters at baseline. 2. RV functional decline is predominantly associated with impairments in RV free wall deformation rather than that of the interventricular septum. 3.Whereas deformational indices predict intraoperative RV dysfunction, traditional linear RV indices had no association with post-operative RV dysfunction.

While RV function is an important determinant of cardiac surgical outcomes, there are few known predictors of acute intraoperative dysfunction. Studies demonstrate that $\mathrm{RV} \mathrm{FAC}<35 \%$ is associated with the greatest risk of postoperative mortality $[2,17]$ and that among patients with preserved RV FAC, those with abnormal longitudinal strain are at higher risk for post-operative mortality [18]. Despite our finding that all linear indices decreased at the time of chest closure, only baseline deformation parameters, which included GLS and free wall strain, predicted intraoperative RV dysfunction. This suggests that RV strain may be an important index to stratify RV dysfunction risk intraoperatively, and may have important clinical implications. Regarding prevalence of RV dysfunction preoperatively, we found that a large number of patients had RV dysfunction at time of surgery (38\%). This prevalence is similar to that reported in the literature: for example, Lella et al. showed that CMR-evidenced RV dysfunction occurred in 44\% (48/109) among patients undergoing elective CABG and valve surgery [19]. Similarly, Haddad et al. demonstrated echo-evidenced RV dysfunction to occur in $22 \%(11 / 50)$ patients undergoing aortic or mitral valve surgery [17]. Our population, the majority of whom are undergoing CABG and/or valve surgery, had similar high prevalence of RV dysfunction pre-operatively.

Previous studies demonstrate a decline in RV function measured by $2 \mathrm{D}$ indices including TAPSE and $\mathrm{S}^{\prime}$ with transthoracic echocardiography (TTE) 3-6 months after surgery. This may be the result of intraoperative factors such as ischemia, pericardial opening, and myocardial stunning secondary to poor protection during $\mathrm{CPB}$ [20]. However, other studies report that RV systolic function was preserved after cardiac surgery, as measured by three-dimensional (3D) TEE and 3D RVEF. Interestingly, Unsworth et al. evaluated TAPSE and S' after pericardial opening and found that these declined acutely intraoperatively, which supports the hypothesis that a geometric, rather than a functional, change occurs to the RV during surgery [3]. Similar to the above finding, preservation of FAC intraoperatively has been linked to a decrease in TAPSE in the setting of increased right-sided filling pressures after CPB [21]. To our knowledge, this is the most comprehensive study of changes in RV systolic function intraoperatively with correlation of changes in 2D indices with regional and global RV strain. We demonstrate that intraoperative RV systolic function significantly declines across all parameters; in particular, GLS significantly predicts subnormal RV function at the end of the surgery. Our TEE measurements were taken before sternotomy and after chest closure, which suggests that changes in RV indices were due to functional, rather than geometric differences.

At present, 2D STE is a relatively new imaging technique that is not routinely used intraoperatively. Unlike Doppler interrogation, strain measured by $2 \mathrm{D}$ is angle independent. Therefore, it may be more accurate and easily applied than tissue Doppler interrogation (TDI). However, 2D STE is dependent on image quality and has lower temporal resolution than TDI. While 2D STE is used to demonstrate subclinical LV dysfunction independent of changes in ejection fraction, it is not yet routinely used to characterize RV dysfunction. Our study demonstrates that it is feasible to use strain as a comparable index to predict RV function in the intraoperative period. We found that free-wall strain, septal strain, global strain, and baseline deformation predicted intraoperative dysfunction [20].

Our study had several limitations. First, 3D RV imaging was not performed routinely as part of this protocol and therefore the effect of cardiac surgery on RV volumes and global EF is not assessed here. Second, the impact of RV dysfunction on post-operative morbidity and mortality is not assessed though it should be noted that intraoperative RV dysfunction has been linked to adverse outcomes in prior studies $[1,2]$. Lastly, this study tested immediate intraoperative RV function rather than RV function over time. 
Future studies evaluating long-term effects of cardiac surgery on the RV are warranted.

\section{Conclusions}

Global and regional RV function, as measured by 2D indices and strain, acutely decline intraoperatively. Moreover, 2D STE of the RV at baseline predicts intraoperative RV dysfunction whereas conventional techniques do not. These findings add to the growing body of literature demonstrating that RV function is significantly impaired during cardiac surgery and suggests that deformational imaging provides incremental value in predicting those who will develop RV dysfunction. The ability to predict this dysfunction could help identify those patients in whom support is needed intraoperatively.

\section{Abbreviations \\ 2D STE: Two-dimensional speckle tracking echocardiography; 3D: Three- dimensional; BMl: Body mass index; CABG: Coronary artery bypass graft; CPB: Cardiopulmonary bypass; CV: Cardiovascular; EDS: End systolic volume; EDV: End diastolic volume; EF: Ejection fraction; FAC: Fractional area change GLS: Global longitudinal strain; LV: Left ventricular; NYHA: New York Heart Association; PADP: Pulmonary artery diastolic pressure; PALACS: Posterior Left pericardiotomy for the prevention of postoperative Atrial fibrillation after Cardiac Surgery; PASP: Pulmonary artery systolic pressure; RAP: Right atrial pressure; RV: Right ventricular; S': Peak systolic velocity; TAPSE: Tricuspid annular plane systolic excursion; TDI: Tissue Doppler interrogation; TEE: Transesophageal echo; TTE: Transthoracic echocardiography}

\section{Acknowledgements}

Not applicable.

\section{Authors' contributions}

LQR was involved in the design of the study and collection, analysis, and interpretation of data and was a major contributor in writing the manuscript. BY was involved in the analysis and interpretation of data and in writing the manuscript. CA was involved in the analysis and interpretation of data and in writing the manuscript. MCP was involved in the interpretation of data and in writing the manuscript. LRB was involved in analysis of data and in writing the manuscript. RBD was involved interpretation of data and in writing the manuscript. LNG was involved in the design of the study and collection of data and in writing the manuscript. JWW was involved in the analysis and interpretation of data and in writing the manuscript. MG involved in the design of the study and collection, analysis, and interpretation of data and was a major contributor in writing the manuscript. JK involved in the design of the study and collection, analysis, and interpretation of data and was a major contributor in writing the manuscript. All authors read and approved the final manuscript.

\section{Funding}

NIH 1 K23 HL 140092-01 (JK), Bruce B. Lerman Clinical Scholar Award (JK). MRTG-CT-08-15-2018 (LR). Funding was used in the analysis, and interpretation of data and in writing the manuscript.

\section{Availability of data and materials}

The datasets generated and/or analyzed during the current study are not publicly available due to institutional restrictions from the Weill Cornell medicine institutional review board.

\section{Ethics approval and consent to participate}

This study was part of the established protocol PALACS, which was approved by the Weill Cornell institutional review board (reference number 1502015867)

\section{Consent for publication}

Not applicable.

\section{Competing interests}

The authors declare that they have no competing interests.

\section{Author details}

${ }^{1}$ Department of Anesthesiology, Weill Cornell Medicine/New York Presbyterian, New York, NY, USA. ²Department of Medicine/Cardiology Division, Weill Cornell Medical College, 525 East 68th Street, New York, NY 10021, USA. ${ }^{3}$ Department of Cardiothoracic Surgery, Weill Cornell Medicine/ New York Presbyterian, New York, NY, USA.

Received: 17 January 2019 Accepted: 29 May 2019

Published online: 07 June 2019

\section{References}

1. Bootsma IT, de Lange F, Koopmans M, Haenen J, Boonstra PW, Symersky T, Boerma EC. Right ventricular function after cardiac surgery is a strong independent predictor for long-term mortality. J Cardiothorac Vasc Anesth. 2017;31(5):1656-62.

2. Maslow AD, Regan MM, Panzica P, Heindel S, Mashikian J, Comunale ME. Precardiopulmonary bypass right ventricular function is associated with poor outcome after coronary artery bypass grafting in patients with severe left ventricular systolic dysfunction. Anesth Analg. 2002; 95(6):1507-18 table of contents.

3. Unsworth B, Casula RP, Kyriacou AA, Yadav H, Chukwuemeka A, Cherian A, Stanbridge Rde L, Athanasiou T, Mayet J, Francis DP. The right ventricular annular velocity reduction caused by coronary artery bypass graft surgery occurs at the moment of pericardial incision. Am Heart J. 2010;159(2):314-22.

4. Okada DR, Rahmouni HW, Herrmann HC, Bavaria JE, Forfia PR, Han Y. Assessment of right ventricular function by transthoracic echocardiography following aortic valve replacement. Echocardiography. 2014;31(5):552-7.

5. Raina A, Vaidya A, Gertz ZM, Susan C, Forfia PR. Marked changes in right ventricular contractile pattern after cardiothoracic surgery: implications for post-surgical assessment of right ventricular function. J Heart Lung Transplant. 2013;32(8):777-83.

6. Tamborini G, Muratori M, Brusoni D, Celeste F, Maffessanti F, Caiani EG, Alamanni F, Pepi M. Is right ventricular systolic function reduced after cardiac surgery? A two- and three-dimensional echocardiographic study. Eur J Echocardiogr. 2009;10(5):630-4.

7. Motoki H, Borowski AG, Shrestha K, Hu B, Kusunose K, Troughton RW, Tang $\mathrm{WH}$, Klein AL. Right ventricular global longitudinal strain provides prognostic value incremental to left ventricular ejection fraction in patients with heart failure. J Am Soc Echocardiogr. 2014;27(7):726-32.

8. Kim J, Alakbarli J, Yum B, Tehrani NH, Pollie MP, Abouzeid C, Di Franco A, Ratcliffe MB, Poppas A, Levine RA, et al. Tissue-based markers of right ventricular dysfunction in ischemic mitral regurgitation assessed via stress cardiac magnetic resonance and three-dimensional echocardiography. Int J Cardiovasc Imaging. 2019;35(4):683-93.

9. Motoji Y, Tanaka H, Fukuda Y, Ryo K, Emoto N, Kawai H, Hirata K. Efficacy of right ventricular free-wall longitudinal speckle-tracking strain for predicting long-term outcome in patients with pulmonary hypertension. Circ J. 2013;77(3):756-63.

10. Lemarie J, Huttin O, Girerd N, Mandry D, Juilliere Y, Moulin F, Lemoine S, Beaumont M, Marie PY, Selton-Suty C. Usefulness of speckle-tracking imaging for right ventricular assessment after acute myocardial infarction: a magnetic resonance imaging/echocardiographic comparison within the relation between aldosterone and cardiac remodeling after myocardial infarction study. J Am Soc Echocardiogr. 2015;28(7):818-827 e814.

11. Carluccio E, Biagioli P, Alunni G, Murrone A, Zuchi C, Coiro S, Riccini C, Mengoni A, D'Antonio A, Ambrosio G. Prognostic value of right ventricular dysfunction in heart failure with reduced ejection fraction: superiority of longitudinal strain over tricuspid annular plane systolic excursion. Circ Cardiovasc Imaging. 2018;11(1):e006894.

12. Abouarab AA, Leonard JR, Ohmes LB, Lau C, Rong LQ, Ivascu NS, Pryor KO, Munjal M, Crea F, Massetti M, et al. Posterior left pericardiotomy for the prevention of postoperative atrial fibrillation after cardiac surgery (PALACS): study protocol for a randomized controlled trial. Trials. 2017;18(1):593.

13. Kim J, Di Franco A, Seoane T, Srinivasan A, Kampaktsis PN, Geevarghese A, Goldburg SR, Khan SA, Szulc M, Ratcliffe MB, et al. Right ventricular dysfunction impairs effort tolerance independent of left ventricular function 
among patients undergoing exercise stress myocardial perfusion imaging Circ Cardiovasc Imaging. 2016;9(11):e005115.

14. Kim J, Srinivasan A, Seoane T, Di Franco A, Peskin CS, McQueen DM, Paul TK, Feher A, Geevarghese A, Rozenstrauch M, et al.

Echocardiographic linear dimensions for assessment of right ventricular chamber volume as demonstrated by cardiac magnetic resonance.

J Am Soc Echocardiogr. 2016;29(9):861-70.

15. Rudski LG, Lai WW, Afilalo J, Hua L, Handschumacher MD, Chandrasekaran K Solomon SD, Louie EK, Schiller NB. Guidelines for the echocardiographic assessment of the right heart in adults: a report from the American Society of Echocardiography endorsed by the European Association of Echocardiography, a registered branch of the European Society of Cardiology, and the Canadian Society of Echocardiography. J Am Soc Echocardiogr. 2010;23(7):685-713 quiz 786-688.

16. Lang RM, Badano LP, Mor-Avi V, Afilalo J, Armstrong A, Ernande L, Flachskampf FA, Foster E, Goldstein SA, Kuznetsova T, et al. Recommendations for cardiac chamber quantification by echocardiography in adults: an update from the American Society of Echocardiography and the European Association of Cardiovascular Imaging. Eur Heart J Cardiovasc Imaging. 2015;16(3):233-70.

17. Haddad F, Denault AY, Couture P, Cartier R, Pellerin M, Levesque S, Lambert J, Tardif JC. Right ventricular myocardial performance index predicts perioperative mortality or circulatory failure in high-risk valvular surgery. J Am Soc Echocardiogr. 2007;20(9):1065-72.

18. Ternacle J, Gallet R, Champagne S, Teiger E, Gellen B, Dubois Rande JL, Gueret P, Lim P. Changes in three-dimensional speckle-tracking-derived myocardial strain during percutaneous coronary intervention. J Am Soc Echocardiogr. 2013;26(12):1444-9.

19. Lella LK, Sales VL, Goldsmith Y, Chan J, Iskandir M, Gulkarov I, Tortolani A, Brener SJ, Sacchi TJ, Heitner JF. Reduced right ventricular function predicts long-term cardiac re-hospitalization after cardiac surgery. PLoS One. 2015;10(7):e0132808.

20. Maffessanti F, Gripari P, Tamborini G, Muratori M, Fusini L, Alamanni F, Zanobini M, Fiorentini C, Caiani EG, Pepi M. Evaluation of right ventricular systolic function after mitral valve repair: a two-dimensional Doppler, speckle-tracking, and three-dimensional echocardiographic study. J Am Soc Echocardiogr. 2012:25(7):701-8

21. Denault AY, Couture P, Beaulieu Y, Haddad F, Deschamps A, Nozza A, Page $P$, Tardif JC, Lambert J. Right ventricular depression after cardiopulmonary bypass for Valvular surgery. J Cardiothorac Vasc Anesth. 2015;29(4):836-44.

\section{Publisher's Note}

Springer Nature remains neutral with regard to jurisdictional claims in published maps and institutional affiliations.

Ready to submit your research? Choose BMC and benefit from:

- fast, convenient online submission

- thorough peer review by experienced researchers in your field

- rapid publication on acceptance

- support for research data, including large and complex data types

- gold Open Access which fosters wider collaboration and increased citations

- maximum visibility for your research: over $100 \mathrm{M}$ website views per year

At BMC, research is always in progress.

Learn more biomedcentral.com/submissions 